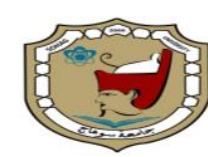

Sohag University
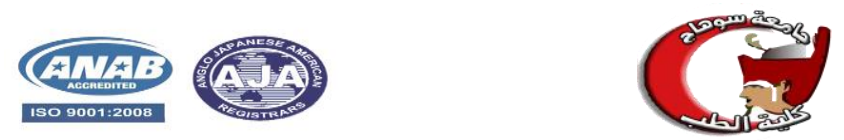

\title{
Relationship between Demodex spp. infestation and acne disease
}

\author{
Noha Sammer Ahmed, Nada Abd El-Fattah El-Nadi, wafaa \\ mohamed Abd Elmaged, Esraa Omar Ali,
}

Department of Medical Parasitology, Faculty of Medicine, Suhag University

\begin{abstract}
:
Background: Demodex mites present on the skin of healthy individuals. Demodex mites in high densities may play a pathogenic role.

Aims: To evaluate the correlation between Demodex infestation and acne vulgaris.

Setting: Outpatient Clinic of Dermatology Department, Faculty of Medicine, Sohag University.

Patients and methods: One hundred patients diagnosed with acne and an equal number of healthy volunteers (with age and sex matching) as control groups were enrolled in this study. Skin scrapping was taken in the patient and the control groups. Samples were

examined by the light microscope, and Demodex were counted.
\end{abstract}

Results: regarding gender and age, no significant difference was present between the patients and controls $(p>0.05)$. Demodex infestation was higher in patients than in controls $(p=0.001)$. no statistically significant relationship between age, sex, family history, presence of animal at home, or severity of acne and the positivity of Demodex mites ( $\mathrm{p}$-value for all > 0.05).

Conclusion: Acne vulgaris is significantly correlated with Demodex infestation.

Key Words: Demodex infestation, Acne vulgaris, Skin scrapping.

\section{INTRODUCTION}

Demodicidae is the family to which Demodex mite belongs to. Demodex foliculorum and Demodex brevis are divided into two types dermal and folicular (1). The parasite prefers the facial area. They may be found on healthy skin but with a density of $<5$ mites/cm2.the clinical manifestations (acne, rosacea, perioral dermatitis, and seborrheic dermatitis are skin diseases claimed to be caused by Demodex (3). , or when more than 5 mites $/ \mathrm{cm} 2$ are present or when they present deeply in the dermis are necessary to diagnose Demodex infestation (2).

Acne is a disease of the pilosebaceous unit presented by comedones, papules, pustules, nodules, and scarring in many cases(4). Although acne is not a dangerous disease, it can lead to Psychological problems due to facial scars (5).

\section{Aims of the Study:}

Our study was done to find the correlation between acne vulgaris and its severity and Demodex mites.

\section{Patients and methods:}

The study was done in the Parasitology Department and Dermatology outpatients clinic, Faculty of Medicine, Sohag University. One hundred patients diagnosed with acne and an equal number of healthy volunteers (with age and sex matching) as control groups were enro- 
lled in this study. They were taken from the outpatient clinics of Dermatology, Venereology and Andrology Departments, Faculty of Medicine, Sohag University Hospitals. The study was agreed upon by the Local Ethics Committee of the university. Informed consent was taken from each patient.

All of the acne patients had comedones; In this study, the following patients Excluded: patients without comedone, patients $<18$ years old, menstrual disturbances, acne caused by a drug, cosmetic acne, presence of any chronic disease, taking topical or systemic steroids, topical acaricide, or immunesuppressive drugs.

The healthy group was $\geq 18$ years old, had no skin disease on either the face or the body, had no itching, and not using topical steroids, systemic steroids, or immuneosuppressive drugs.

\section{Grading of acne severity}

The acne severity was graded from 1 to 4 according to the Global Acne Severity Scale (GASS) proposed by (6). Forehead, each cheek, nose, chin, chest, and upper back are sites to be examined and available for scrapping.

\section{Collection and examination of samples}

One sample was obtained from the lesion using skin scraping with potassium hydroxide preparation. patients cleaned their faces with a gentle cleanser and water before the test. After the skin dried, a sterile sharp blade was scraped on a one-square centimeter area of the right cheek.

The accumulated debris or scale was collected, a drop of $20 \%$ potassium hydroxide was added according to(7) and the sample was covered and examined for Demodex by light microscopy as shown in figures 1,2. The parasites on each slide were calculated to evalu- ate Demodex density and its correlation with Demodex severity. patients were informed about the steps of skin scraping. In the acne group, skin scraping was obtained from different acne lesions. In the control group, Skin scraping was taken from the chin or forehead.

\section{Statistical analysis:}

Data were studied utilizing a Statistical Program for Social Science (SPSS) version 18.0. Quantitative data were evinced as mean \pm standard deviation $(\mathrm{M} \pm-$ SD) while qualitative data were evinced as frequency and percentage $\mathrm{No}(\%)$. Chi-square test: was utilized in compareson of non-parametric data. A one-way analysis of variance (ANOVA), utilized in comparison of more than two means. P-values were established statistically significant at $\mathrm{P}<0.05$.

\section{Results:}

Demographic data of the patients and controls are present in Table 1. This table shows no statistically significant difference (p-value $>\mathbf{0 . 0 5}$ ) between studied groups as regard age and sex. In the patient's group, there were $28 \%$ males and $72 \%$ females while in the control group there were $40 \%$ males and $60 \%$ females. The mean age of the patient group was $23.7 \pm 4.3$ years while the mean age of the control group was 27.8 \pm 6.7 years.

Table 1 shows no statistically significant difference ( $\mathrm{p}$-value $=0.111$ ) between studied groups as regard presence of animal at home (22\% Vs $32 \%)$. As regards the degree of acne in the patient's group, our study shows $52 \%$ of a mild degree, $26 \%$ of moderate degree, and $22 \%$ of a severe degree of acne.

\section{The incidence and density of Demodex mites:}

Table 2 shows a highly statistically significant difference (p-value $<\mathbf{0 . 0 0 1}$ ) between studied groups as regards the 
SOHAG MEDICAL JOURNAL

Vol. 25 No. 2 April 2021

positivity of Demodex. In the patient's group, there were $44 \%$ of patients positive for Demodex \& $56 \%$ of patients negativer while in the control group there were $16 \%$ positive $\& 84 \%$ negative.

Table 3 shows the density of Demodex mites in the patients. patients with severe acne had more Demodex mites than patients with mild and moderate acne

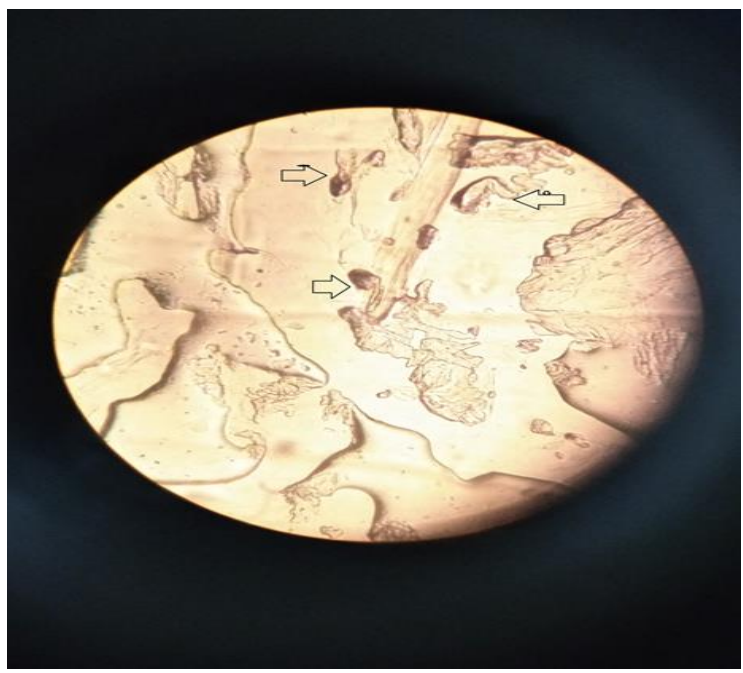

Figure 1. Species infection:Demodex folliculorum from skin scrap by wet mount (100x).
Relationship between Demodex spp. infestation Noha Sammer Ahmed with statistically significant differences between them.

Table 4 shows no relationship between age, sex, family history, presence of animal at home, or severity of acne and the incidence of Demodex mites (p-value for all > 0.05). This means that the positivity of Demodex acts as an independent risk factor for acne disease.

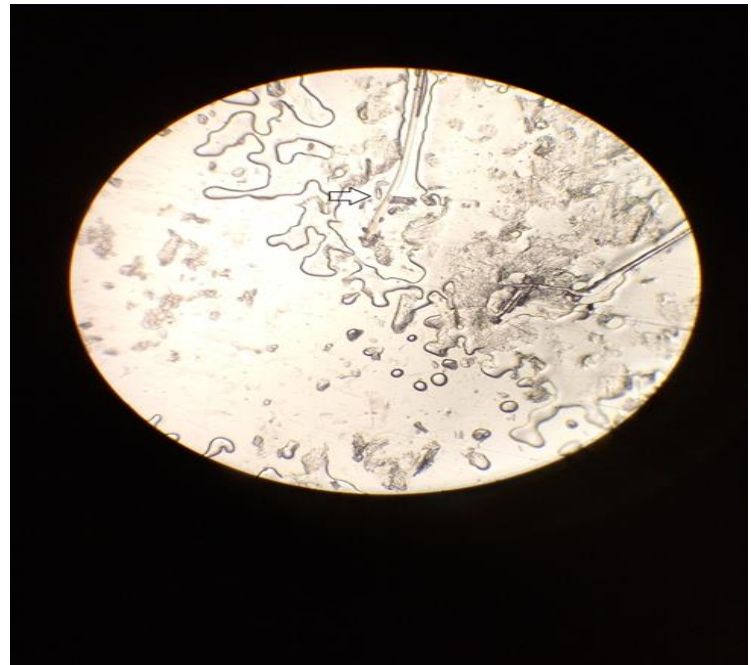

Figure 2. Species infection: Demodex folliculorum from skin scrap by wet mount(40x).

\begin{tabular}{|l|l|l|l|l|l|l|}
\hline \multicolumn{2}{|c|}{} & $\begin{array}{l}\text { Patients } \\
(\mathrm{N}=100)\end{array}$ & $\begin{array}{l}\text { Control } \\
(\mathrm{N}=100)\end{array}$ & P-value \\
\hline Age (years) & Mean \pm SD & $\begin{array}{l}25.6 \\
\pm 4.06\end{array}$ & $\begin{array}{l}27.8 \\
\pm 6.7\end{array}$ & 0.051 NS \\
\hline \multirow{3}{*}{ Sex } & Male & 28 & $28 \%$ & 40 & $40 \%$ & \multirow{2}{*}{0.073 NS } \\
\cline { 2 - 7 } Presence of animal at home & Female & 72 & $72 \%$ & 60 & $60 \%$ & \\
\cline { 2 - 7 } & Yes & 22 & $22 \%$ & 32 & $32 \%$ & \multirow{3}{*}{0.111 NS } \\
\cline { 2 - 7 } & No & 78 & $78 \%$ & 68 & $68 \%$ & \\
\hline
\end{tabular}

Table 1. Description of demographic data in studied groups

No statistically significant difference was found on this table (p-value $>\mathbf{0 . 0 5}$ ) between groups as regard age, sex, and presence of animals at home.

\begin{tabular}{|l|l|l|l|l|}
\hline \multicolumn{2}{|c|}{} & $\begin{array}{l}\text { Patients } \\
(\mathrm{N}=100)\end{array}$ & Control(N=100) & P-value \\
\hline \multirow{2}{*}{ Demodex } & Positive & $44 \%$ & $16 \%$ & \multirow{2}{*}{$<0.001 \mathrm{HS}$} \\
\cline { 2 - 4 } & Negative & $56 \%$ & $84 \%$ & $<$ \\
\hline
\end{tabular}

Table 2.Prevalence of Demodex infection in studied groups This table shows a highly statistically significant difference (p-value < 0.001) between studied groups as regards the Prevalence of Demodex infection. 


\begin{tabular}{|l|l|l|l|l|l|l|}
\hline \multicolumn{2}{|c|}{} & \multicolumn{2}{l|}{$\begin{array}{l}\text { Patients } \\
(\mathrm{N}=44)\end{array}$} & \multicolumn{2}{l|}{$\begin{array}{l}\text { Control } \\
(\mathrm{N}=16)\end{array}$} & \multirow{2}{*}{ P-value } \\
\hline \multirow{4}{*}{ Number of Demodex / cm } & I & 12 & $27.3 \%$ & 13 & $81.2 \%$ & \\
\cline { 2 - 6 } & II & 12 & $27.3 \%$ & 3 & $18.7 \%$ & \multirow{3}{*}{$\mathbf{0 . 0 0 1} S$} \\
\cline { 2 - 6 } & III & 10 & $22.7 \%$ & 0 & $0 \%$ & \\
\cline { 2 - 6 } & IV & 10 & $22.7 \%$ & 0 & $0 \%$ & \\
\hline
\end{tabular}

Table3. Comparison between groups as regard density of Demodex mites

This table shows a statistically significant difference $(\mathbf{p}$-value $=\mathbf{0 . 0 0 1})$ between studied groups as regards the number of Demodex $/ \mathrm{cm}$.

\begin{tabular}{|c|c|c|c|c|c|c|}
\hline \multirow{2}{*}{\multicolumn{2}{|c|}{ Patients group }} & \multicolumn{4}{|c|}{ Demodex } & \multirow{3}{*}{$\begin{array}{l}\text { P-value } \\
0.834 \mathrm{NS}\end{array}$} \\
\hline & & \multirow{2}{*}{\multicolumn{2}{|c|}{$\begin{array}{l}\begin{array}{l}\text { Positive } \\
(\mathrm{N}=44)\end{array} \\
23.4 \pm 3.3\end{array}$}} & \multirow{2}{*}{\multicolumn{2}{|c|}{$\begin{array}{l}\begin{array}{l}\text { Negative } \\
(\mathrm{N}=56)\end{array} \\
23.9 \pm 4.9\end{array}$}} & \\
\hline Age (years) & Mean \pm SD & & & & & \\
\hline \multirow[b]{2}{*}{ Sex } & Male & 12 & $27.3 \%$ & 16 & $28.6 \%$ & \multirow[b]{2}{*}{$0.886 \mathrm{NS}$} \\
\hline & Female & 32 & $72.7 \%$ & 40 & $71.4 \%$ & \\
\hline \multirow[t]{2}{*}{ Family history } & Yes & 20 & $45.5 \%$ & 34 & $60.7 \%$ & \multirow[b]{2}{*}{$0.129 \mathrm{NS}$} \\
\hline & No & 24 & $54.5 \%$ & 22 & $39.3 \%$ & \\
\hline \multirow[b]{2}{*}{ Animal at home } & Yes & 10 & $22.7 \%$ & 12 & $21.4 \%$ & \multirow[b]{2}{*}{$0.876 \mathrm{NS}$} \\
\hline & $\mathrm{No}$ & 34 & $77.3 \%$ & 44 & $78.6 \%$ & \\
\hline \multirow{3}{*}{ Degree of acne } & Mild & 24 & $54.5 \%$ & 28 & $50.0 \%$ & \multirow{3}{*}{$0.802 \mathrm{NS}$} \\
\hline & Moderate & 10 & $22.7 \%$ & 16 & $28.6 \%$ & \\
\hline & Severe & 10 & $22.7 \%$ & 12 & $21.4 \%$ & \\
\hline
\end{tabular}

Table4. Comparison between infected and noninfected patients as regards demographic data.

This table shows no statistically significant differences $(\mathbf{p}$-value $<\mathbf{0 . 0 5})$ between studied groups as regard age, sex, family history, presence of animal at home, and severity of acne.

\section{Discussion:}

In the current study, we found that $D e$ modex mite positive ( $\geq 5$ mites/cm 2$)$ in $44 \%$ of the patients and $16 \%$ of the controls. The prevalence of Demodex infection was found to be higher in the patients compared to the controls with a statistically significant difference between them (p-value $<\mathbf{0 . 0 0 1}$ ).

The results of our study were supported by a previous study (8). In which 210 patients with acne and 150 healthy controls without any skin diseases were enrolled. They observed that Demodex mite positivity was found to be $62.4 \%$ in the patients and $16.7 \%$ in the controls (9).Comparative studies were done to det-ermine this relationship and showed th-at Demodex positivity was $11.8 \%$ in 101 patients(9). another study was don-e also and positive samples were $15.38 \%$ of 78 patients. a metaanalysis was carried on the same issue in which 63 articles were evaluated and 48 found a positive association (10).

The higher number of Demodex mites found in $54.85 \%$ of patients; it was $31.54 \%$ higher than in the controls $(O R=2.80 ; 95 \%$ CI: 2.34-3.36)(11). 
However, other authors didn't find a correlation and concluded that the Demodex mites were not correlated with acne vulgaris(12).

Also, there was no statistically significant relation $(\mathbf{p}$-value $=\mathbf{0 . 8 0 2})$ between Demodex positivity and the degree of acne patients group in our study. There were $52 \%$ of mild degrees, $26 \%$ of moderate degrees, and $22 \%$ of severe degrees of acne in the patient's group. Another study found the same result (13).

In our study, no statistically significant relation ( $\mathbf{p}$-value $\mathbf{= 0 . 8 3 4}$ for age and 0.886) between Demodex positivity in the patient's group in terms of age and sex. Another study also found no correlation between gender and Demodex infestation, also there was no statistically significant relation $(\mathbf{p}$-value $=$ 0.006) between Demodex positivity and sex in the control group(14).

A new finding in this work that there was no statistically significant difference $(\mathbf{p}$-value $\mathbf{= 0 . 0 9 2}$ ) between groups concern with the presence of animals at home. In the patient's group, there were $22 \%$ of patients had animals in their home while in the control group there were $32 \%$ had animals in their home. This was consistent with a study carried on the same issue(13)

Also, there was no statistically significant relation $(\mathbf{p}$-value $\mathbf{= 0 . 8 0 2})$ betwee$\mathrm{n}$ Demodex positivity and the degree of acne patients group in our study. There were $52 \%$ of a mild degree, $26 \%$ of moderate degree, and $22 \%$ of a severe degree of acne in the patient's grou$\mathrm{p}$ which was the same finding in another study(13).

On the other hand, there was no statistically significant relation (p-value =0.129) between Demodex positivity and family history of acne in our study despite that the study found that the Demodex positivity was higher in patients with a family history of acne this may
Relationship between Demodex spp. infestation Noha Sammer Ahmed

be due to these study found that the most significant family member with acne history was the mother, followed by the father, but other relatives showed no association in p-value. in our study, we didn't classify them.

\section{Conclusion:}

Acne vulgaris is significantly related to Demodex infestation. Examination and therapy for Demodex mites should be considered when regular treatment options for acne vulgaris are ineffective.

\section{Conflict of Interest:}

The authors of the study have no conflict of interest related to this publiccation.

\section{References:}

1. Rusiecka Ziółkowska J, Nokiel M, Fleischer M. Demodex --- an oldpathogen or a new one? Adv Clin Exp Med. 2014;23:295---8.

2. Aktas, Karabay E, Aksu C, erman A. Demodex folliculorum infestations in common facial dermatoses: acne vulgaris, rosacea, seborrheic dermatitis. A Bras Dermatol. 2020;95:187---93.

3. Aytekin S, Ş Y, Göktay F. 2017. Demodex infestations. Turkiye Klinikleri Journal of DermatologySpecial Topics. 10:169-174.

4. .Tilki E, Zeytun E, Doğan S. 2017. Prevalence and density of Demodex folliculorum and Demodex brevis (Acari: Demodicidae) in Erzincan province. Acta Parasitologica Turcica. 41:80-86.

5. Tan JKL, Bhate K. 2015. A global perspective on the epidemiology of acne. British Journal of Dermatology. 172:3-12.

6. Doshi A, Zaheer A, Stiller MJ. A comparison of current acne grading systems and proposal of a novel system. International journal of dermatology. 1997 Jun;36(6):416-8.

7. Bunyaratavej S, Rujitharanawong $C$, Kasemsarn $P, \quad B o o n c h a i \quad W$, Muanprasert $C, \quad M a t t a p a n \quad L$, 
SOHAG MEDICAL JOURNAL

Vol. 25 No. 2 April 2021

Leeyaphan C. Skin scrapings versus standardized skin surface biopsy to detect Demodex mites in patients with facial erythema of uncertain cause - a comparative study. Indian J Dermatol Venereol Leprol 2016;82:519-22.

8. Zeytun $E$ and Yazicib $M$. Incidence and density of Demodex folliculorum and Demodex Brevis (Acari: Demodicidae) in patients with acne in the province of Erzincan, Turkey. INTERNATIONAL JOURNAL OF ACAROLOGY 2019; 45(3):108-112.

9. Baysal V, Aydemir M, Yorgancıgil B, Yıldırım M. Akne vulgaris etyopatogenezinde D. folliculorum'ların rolünün araştırılması. Türkiye Parazitol Derg 1997; 21: 265-8.

10.Polat E, Aygün G, Ergin R, Aslan M, Kutlubay Z, Altas K. The role of Demodex folliculorum and Propionibacterium acnes in the pathogenesis of acne vulgaris. Türkiye Parazitol Derg. 2003;27:148-51.
Relationship between Demodex spp. infestation Noha Sammer Ahmed

11.. Zhao YE, Hu L, Wu LP, Ma XJ. A meta-analysis of the association between acne vulgaris A. Demodex infestation. J Zhejiang Univ-Sci B. 2012;13:192---202.32

12..Okyay P, Ertabaklar H, Save E, Erfug $S$. Prevalence of Demodex folliculorum in young adults: relation with sociodemographic/hygienic factors and acne vulgaris. J Eur Acad Dermatol Venereol 2006; 20: 474-6.

13.Akçınar UG, Ünal E, Al FD. Demodex spp. as a possible etiopathogenic factor of acne and relation with acne severity and type. Advances in Dermatology and Allergology/Postępy Dermatologii i Alergologii. 2018 Apr;35(2):174.

14.Dokuyucu R, Kaya OA, Yula E, Ustun I, Bayram F, Gokce C. The presence of Demodex folliculorum in various obese groups according to BMI levels. Arch Iran Med 2016; 19: 210-4 